\title{
Analysis of Impact of Urban Agglomeration Planning of Middle and Lower Yangtze River on International Trade Development in Central China
}

\author{
Chuxin Yang \\ Hunan International Business Vocational, Changsha, 410201, China
}

Keywords: Central China; International trade development; Impact analysis

\begin{abstract}
After implementation of strategy for promoting the rising of Central China, central China seizes opportunities and forges ahead. In order to promote international trade development in the central region, implementation of urban agglomerations of middle and lower Yangtze River shall be vigorously promoted, aiming at promoting its commercial development. Through analyzing urban trade factors affected international trade development in the central region, this paper summarizes advantages, opportunities, achievements and prospects of international trade development of urban agglomeration.
\end{abstract}

\section{Introduction}

Urban agglomeration is the highest spatial organization when urbanization development gets to mature period, which plays important role in promotion of urbanization development and regional economic growth. During the 11th Five-Year Plan Period, the State Council of PRC put forwards instructions on strategy for promoting the rising of Central China and the provinces of central China actively responds and puts forward solution for building urban agglomeration as the core part. It is a grand project for promoting urban agglomerations of middle and lower Yangtze River due to affected by many factors, such as restriction of economic conditions, making full use of the geographical advantage, strengthening cooperation of cities along the Yangtze River and overall competitiveness of urban agglomerations by complementing each other with advantages.

\section{Current situation of urban agglomerations of middle and lower Yangtze River}

Urban agglomeration of the middle and lower reaches of the Yangtze River is super-huge type urban agglomeration, covering Wuhan urban agglomeration, Changsha-Zhuzhou-Xiangtan urban agglomeration, Poyang lake urban agglomeration, which is one of support of three big cross-regional urban agglomerations in Yangtze River Economic Zone. Of which urban agglomeration in the Middle Reaches of the Yangtze River with Wuhan, Changsha and Nanchang as center is key area for implementing strategy of promoting the rising of Central China, deepening reform and opening up in an all-round way and promoting new-type urbanization and occupies important position in pattern of reform and development of China. Urban agglomeration in the Middle Reaches of the Yangtze River connects Pearl River Delta and Yangtze River delta based on Yangtze River. Of which central position of Wuhan is about less than 300 kilometers from Changsha and Nanchang, where has large area with complicated terrain that is about several times as that of Yangtze River delta and Pearl River delta. In addition, high-speed rail let transportation more developed. Strengthen the center position of Wuhan, Changsha, Nanchang has important significance for building key cities and promoting the rising of Central China. In 2015, the program of latest urban agglomeration points out China will classify urban agglomeration in the Middle Reaches of the Yangtze River and Chengdu-Chongqing urban agglomeration as five urban agglomerations, which make a clear prospect of economic development of central China. 


\section{Benefited Areas and Primary Mission of International Trade Development of Middle and Lower Reaches of the Yangtze River urban agglomeration}

\section{Benefited Areas of Trade Development}

Urban agglomerations in the Middle Reaches of the Yangtze River include Wuhan urban agglomeration, Changsha-Zhuzhou-Xiangtan urban agglomeration, Poyang lake urban agglomeration. In terms of geographic location, it is of significance, which can connect to southern and northern region, linking the eastern and western regions. The total land area is about 30.7 square kilometers, which is hundreds of that of Singapore. Such regions cover several key cities at province level of central China, such as Hunan, Hubei, Jiangxi, etc.. The development prospect of cities with Wuhan as center is to be expected.

\section{Primary Mission in Development Process}

First is common development of urban and rural areas. The position of central cities of Wuhan, Changsha, Nanchang with Wuhan as central shall be consolidated. City and countryside integration shall be continued to develop. To make full use of network pattern of economic development of cities along the Yangtze River can strengthen cooperation and communication with neighboring cities and promote new type of urbanization. Second is interconnection of infrastructure. Interconnection of infrastructure like traffic connection between cities, network openness, energy sharing, information exchange has important significance for development of urban agglomeration. Good interconnection environment can improve comprehensive security and support ability of urban agglomeration. This is harmonious development of industry diversity. The development of urban agglomeration relates to diversified communication of industries. Industry shall foster strengths and circumvent weaknesses on the basis of original, developing into excellent industrial cluster via harmonious development. Meanwhile, cross-regional development of industry shall be promoted, modern industry bases shall be enlarged, stepping in development of regional characteristic industry. Fourth is implementation of sustainable development concept. In the context of rapid economic development, the common ideal is to save energy, to promote sustainable development, to build green development view, to construct ecological civilization. The implementation of sustainable development concept can achieve harmonious coexistence of people and nature, which is our common goal. Fifth is to share service. Cities develop together and share resources, communicating in education, health care, etc.. Through strengthening public consciousness, promoting resource sharing, social system of sharing of public service, more benefits of urban agglomerations shall be felt by more people, making a contribution to common prosperity. Sixth is to deepen opening to the outside world. Standing on the new starting point of the opening to the outside world, we shall increase consensus, strengthen confidence and grasp initiative of opening to the outside world and follow the trend of economic globalization. We shall vigorously implement the development strategy of opening to the outside world with an adventurous spirit; establish a platform for conducting domestic and abroad cooperation to improve economic level and promote sound and rapid economic development. In order to smooth implementation of the planning, relevant parties emphasis on positive attitude, clear mind and powerful measures to achieve the planning objectives and tasks on schedule.

\section{Opportunity of International Trade Development of Middle and Lower Reaches of the Yangtze River Urban Agglomeration}

\section{Enhance the links with the Yangtze river delta region}

Wuxi, Suzhou, Nanjing, Nantong of Jiangsu province, Shaoxing, Taizhou, Ningbo, Hangzhou, Huzhou of Zhejiang province and Shanghai and other cities are major cities of Yangtze River delta urban agglomeration in Eastern Coastal Region of China. These cities the highest level of economic development area in China and are areas with highest level of urbanization. The Yangtze River delta has unique geographical advantage; rich land reserve resources and plays important role of strategic status, which creates nearly one fifth GDP and nearly one fourth import-export volume and fiscal revenues by little land and one tenth population. Hence, it has important significance for 
strengthening exchanges and cooperation between China and costal countries. The business of Yangtze River delta region is gradually promoted by market, which is inherent requirement and inevitable trend of regional economic development. With acceleration of development, such region will attract more domestic investors, facing more opportunities and challenges; absorbing more excellent talents and top technology, advanced information that speeds up the development of the middle and lower reaches of the Yangtze river urban agglomeration and increases links with the Yangtze River delta region and promote expansion of foreign trade.

\section{Industrial Transfer caused by Formed Regional Inferior Position}

Eastern coastal region in China has rapid economic development, which is the main force of China's foreign trade. However, the demand for industry development in such regions cannot be satisfied due to restrictions of land resources and energy sources. Such situation can be made up by vast land, rich resources, sufficient labor and low production cost of Midwest China, which indicates that is an irresistible trend for transferring industrial center from eastern to the western region. The situation "emptying the cage, removing the bird" is inevitable and trend of processing zone has transferred from eastern region to Midwest China is obvious. In order to speed up the upgrading of an industrial structure, eastern region actively begins to adjust regional industry layout; to implement regional industrial migration that can spread out resources and labor-intensive industries for focusing on development of high and new technology industry and high-end manufacturing. With gradually improvement of transportation, communications and energy bases of Midwest China, the institutional environment, investment environment, market environment greatly improved. Western development policies implemented by state encourage improving level of social development and consolidating national defence in western China by using remaining economic development ability of East China, which can weaken disadvantage of region and make it becoming a good place for supporting industrial relocation of coastal areas.

\section{Influence on International Trade of Central China}

\section{Important Growth Pole of Rising of Central China}

Urban agglomeration refers to relatively complete urban aggregation constitute of cities at different properties, types and scales through strengthening internal links of cities, relying on certain natural environment and conditions and taking one center city as core. In the context of current economic landscape, urban agglomerations as a new form of space have replaced the original urban development. In the era of rapid economic development, urban agglomeration is the inevitable product of the maturity of the urban economy and engine of economic rapid development. Urban agglomeration is the product of regional economy development, which indicates that the commodities in formed economic circle have certain space of congregation and diffusion.

Close internal connection of urban agglomerations can break regional administrative division, which provides superior information and transportation services; good carrier for industry development and is best choice for developing higher level industry due to strong technical force, technology and capital and low cost advantage. Meanwhile, coordination, development, and communication of cities can provide comprehensive information exchange for regional economic development situation and factors and attract resources for urban agglomeration. A perfect urban agglomeration can properly solve industry homogeneity, distribution of benefits and taxation, local protectionism and other problems, which is benefit for industrial coordination development; scale expanding, resulting in more benefits and important growth pole.

\section{Innovation brings opportunities for competitiveness of Central China}

The growth of city is innovation, especially in current old and new system transformation stage. Innovation is force of urban progress, while the cities refused to growth will have no greater development and will lag behind the trend of economic development. The central region must enhance their ability to innovate, which can achieve rapid growth. Make use of the convenient conditions of urban agglomerations can create a relatively free common market and integrate production factors, labors, merchandising elements and capital elements can achieve best allocation 
of resources, which can attract many companies with innovative capacity. Under the innovation and development, companies shall introduce new business model and management system for seeking higher development. Reform and innovation is a powerful engine that can perfect urban agglomeration in innovation and make urban agglomeration play greater role and create more profits. We shall uses new methods, new methods to solve the problems occurred in development, making urban agglomeration become a birthplace of new ideas, new concept and new system that improve market competitiveness of the central region.

\section{Enhance economic cooperation of fields}

A key feature of economic development in the central region is loose links of economy. Now the trend of Chinese economic development is integration, while loose economy situation in central area has no change and is away from direction of economic integration. Such situation will weaken the overall strength of development of the central region and serious affect the role of the central region in the regional economic development strategy. Therefore, the establishment of urban agglomeration is particularly important. The cohesion of the cities can be improved; integration of economic and development will be enhanced; regional economic pattern can be implemented quickly by such particular system, which can form cooperation among provinces and cities and enhance national economy overall strength.

\section{Meet the Needs of the Eastern Industrial Transfer}

Eastern coastal industries has gradually updated from handicraft industry to electronics industry pattern that is based high-technology industry. In theory, resource-consuming industry and industries with high demand on labor in coastal region shall transfer to central and western regions, while such similar industries have transferred in province instead of central and western regions, such as transferring industries of Zhejiang to west of Zhejiang; industries of Jiangsu from South of Jiangsu to North of Jiangsu; designated transferring region made by Guangdong, which potentially increases competitive pressure of central region receiving central region and hinders the pace of development of the central region. Meanwhile, the competition around the country shall be faced when facing industry transfer. In this case, the central region shall have sufficient competitive strength and good industry prospect to achieve quickly transferring eastern industry to central region. The central and western region in China is at comprehensive development status, of which projects needed revitalization are more and poor system is not conductive to managing investment by state according to actual situation. It shall establish several major regions through overall management, which can gather factors for development on a regional basis to increase attraction of eastern industrial transfer. The construction of central urban agglomeration can meet these factors, which can build central region into a warm land for eastern industrial transfer.

\section{Accelerate the industrial transformation to present characteristic industry form}

In order to keep up with the development of the times, central region shall conduct regional economization. In such region, the population is up to 361 million, accounting for $27.8 \%$ of the country. It is difficult to achieve rapid development of economy due to overpopulation and no pillar industries. In addition, the location of central region is disadvantage, which hinders the industry development and obvious lag behind than that of coastal region (urbanization rate is $40.3 \%$ and the average level of urbanization in the country is $46 \%$ ). A large number of people of central and western regions held up in rural area. If there is no industry transfer of large cities, such labor cannot make such region keep up with pace of national economic reform. To develop urban agglomeration and to strengthen links of cities in central region can form regional economic mode, which can solve Three Rural issues and promote industrialization and urbanization process. In addition, the central region dominated by agriculture shall build dominant industrial groups; construct modern service Industry clusters; develop and expand modem agriculture base; protect agricultural resources and avoid ecological damage and increase land utilization rate to accommodate urban population as many as possible in limited land when promoting urbanization course. Meanwhile, it shall orderly conduct cross-regional industrial transfer and acquisition; speed up industrial restructuring and upgrading and build a modern eco-industrial system with regional characteristics. 


\section{Conclusion}

In order to keep up with the development of the times, urban agglomeration, an emerging system is gradually replacing traditional big cities or economic centers at municipal level. New economic mode based on achieving regional economy can in line with economic globalization. Meanwhile, coordination, development, and communication of cities can provide comprehensive information exchange for regional economic development situation and factors and attract resources for urban agglomeration. A perfect urban agglomeration can properly solve industry homogeneity, distribution of benefits and taxation, local protectionism and other problems, which is benefit for industrial coordination development; scale expanding, resulting in more benefits and important growth pole.

\section{References}

[1] Statistic Bureau of Jiangxi. Research of Development Strategy of Jiangxi Poyang Lake Ecological Economic Zone. Jiangxi Statistics, 2008.

[2] Huang Jiuli, Li Kunwang, Li Defu. Coordination of Real Business Cycle in China. Journal of World Economy, 2011, (09)

[3] Li Lei, Liu Jiu, Zheng Zhaoyang. Yangtze River Delta Integration and Economic Synchronization. Jiangsu Social Sciences, 2011,(02).

[4] Wang Yanjun. Association Study of Economic Fluctuation of China Three Regions and Overall Economic Fluctuations. Finance and Trade Research,2006,(06). 